\title{
Clinical Profile and Outcome of Neonates Admitted to the Neonatal Care Unit in a Rural Teaching Hospital
}

\author{
Shrestha S, ${ }^{1}$ Sindan $N,{ }^{1}$ Kayastha $N,{ }^{1}$ Karki DB, ${ }^{2}$ Jha K, ${ }^{2}$ Thapa SD, ${ }^{2}$ Acharya BD, ${ }^{2}$ Gurung $\mathrm{D}^{3}$ \\ ${ }^{1}$ Department of Paediatrics, Karnali Academy of Health Sciences, Jumla, Nepal, ${ }^{2}$ Department of \\ Orthopedics, Karnali Academy of Health Sciences, Jumla, Nepal, ${ }^{3}$ Department of General Medicine, \\ Karnali Academy of Health Sciences, Jumla, Nepal.
}

Corresponding Author:

Dr Sandeep Shrestha

Karnali Academy of Health Sciences, Jumla, Nepal

Email: sandeepshrsth1@gmail.com

\begin{abstract}
Introduction: Neonatal morbidity and mortality rates reflect efficiency of health services of a country. This study was conducted to identify the clinical profile, pattern of diseases and common causes of mortality and morbidity in neonates admitted to neonatology unit.

Methods: The study was conducted in Neonatal Unit of Karnali Academy of Health Sciences, Jumla for a period of one year from 1st May 2017 to 30th April 2018. Data of all admitted patients were reviewed and analyzed in terms of gender, gestational age, age at presentation, weight, cause of admission and their outcome. Diagnosis was made on clinical examination, radiological findings and laboratory investigations. Data were analyzed using SPSS version 20 .

Results: Out of 153 neonates admitted during the study period, 2 were excluded because of deficient record. Full-term neonates were 122(80.7\%) while preterm were 29 (19.3\%). Low birth weight (LBW) babies were 32 (21.18\%). Neonatal sepsis $91(60.26 \%)$ was the most common cause of hospital admissions followed by meconium aspiration syndrome $21(13.9 \%)$ and prematurity $10(6.62 \%)$. Out of 151 newborns, 112 babies $(74.1 \%)$ were discharged after improvement, 15(9.93\%) left against medical advice, 13(8.6\%) babies were referred to higher centers for intensive care and there were $9(5.9 \%)$ mortalities and $2(1.3 \%)$ got absconded.
\end{abstract}

Conclusions: The majority of neonatal morbidity is due to sepsis, prematurity and respiratory causes. All these causes are preventable to some extent and, can be effectively treated in order to reduce morbidity and mortality.

Keywords: admission; mortality; new born; sepsis.

\section{INTRODUCTION}

Karnali Academy of Health Sciences has been regularly providing Neonatal care services through special baby care unit. The neonatal period is the most vulnerable time for child's survival. ${ }^{1}$ of the 130 million babies born every year, about 4 million die in the neonatal period. ${ }^{2,3}$ Since the Millennium Development Goals were formed, progress towards reducing child mortality accelerated but remained insufficient to achieve MDG- $4{ }^{2}$ The worldwide neonatal mortality rates fall by $47 \%$ between 1990 and 2015 from 36 to 19 deaths per 1,000 live births. Over the same period, the number of newborn babies that died within the neonatal period declined from 5.1 million to 2.7 million. ${ }^{4}$ With the end of MDGs era in 2015, international community has agreed on a new framework, the Sustainable Development Goals (SDGs). ${ }^{5}$ The proposed SDG target for neonatal mortality represents a renewed commitment to the world's newborn: by 2030, end preventable deaths of newborns to $\leq 12$ deaths per 1,000 live births. $^{6}$

Neonatal deaths and stillbirths remain an important health problem in Nepal. Despite efforts made to reduce neonatal deaths, Nepal witnessed a stagnant neonatal mortality rate of 33 per 1000 live births in the preceding 5 years as shown by the 2006 and 2011 NDHS surveys. NDHS Survey of 2016 found neonatal mortality rate of $21 / 1000$ 
live births. ${ }^{7}$ The neonatal disease pattern changes between different places and from time to time even at the same place. ${ }^{8}$ The major causes of neonatal deaths globally were estimated to be infections (35\%), pre-term births (28\%) and asphyxia (23\%). ${ }^{9}$ According to a study done in Nepal, Sepsis is the leading cause of hospital admission (34.5\%) followed by prematurity (23.3\%) and Asphyxia (23.1\%). ${ }^{10}$ Birth asphyxia (31.89\%) was the most common cause of hospital admissions followed by prematurity (26.36\%) and neonatal sepsis (16.91\%) in another study done in Pakistan. ${ }^{11}$

The purpose of this study is to determine and report important causes of admission, incidence and causes of death for a large group of neonates admitted to our Neonatal care unit and manage complications accordingly.

\section{METHODS}

This descriptive observational study was conducted in the Neonatal Unit of Karnali Academy of Health Science, Jumla from 1st May 2017 to $30^{\text {th }}$ Aril 2018. KAHS has 8 bedded NIMCU with 2 phototherapy units, radiant warmer \& an Incubator. All babies admitted to the NIMCU were included in the study. Data on age at admission, gender, gestational age, birth weight, final diagnosis and outcome in regards to whether the newborn was discharged after completion of treatment, discharged on request, left against medical advice (LAMA), referred or expired were collected. Cases whose data were not available were excluded. Data was entered and statistical analysis carried out using SPSS.

\section{RESULTS}

Total number of neonates born within study period was 636.There were 14 cases of early neonatal deaths and 10 still births. So, the perinatal mortality is calculated as 3.7 per 1000 live births. A total of 153 neonates were admitted in the neonatal unit during the study period. All of them met the inclusion criteria but 2 neonates were subsequently excluded because of deficient record. Out of 151 neonates, males were 93 (61.5\%) while females were $58(38.5 \%)$ resulting in a ratio of 1.6:1.

\section{Distribution of study population by gestation}

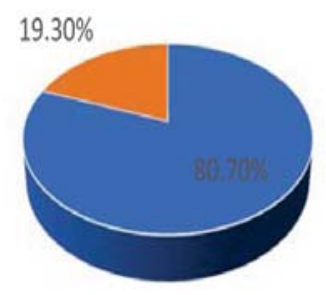

- Term

Figure 1. Distribution of study population by gestation

Regarding birth weight of the babies, 119 (78.82\%) had birth weight more than 2500 grams and $26(17.21 \%)$ with birth weight between 1500$2500 \mathrm{gm}$. There were 5(3.31\%) babies with birth weight between 1000-1500 gm. Altogether low birth weight babies admitted were 32(21.18\%)

\begin{tabular}{|l|l|l|}
\hline \multicolumn{3}{|l|}{ Table 1. Patient Characteristics (n=151) } \\
\hline Birth Weight(gm) & Number(n=151) & Percentage \\
\hline$<1000 \mathrm{gm}$ & 1 & 0.66 \\
\hline $1000-1500 \mathrm{gm}$ & 5 & 3.31 \\
\hline $1500-2500 \mathrm{gm}$ & 26 & 17.21 \\
\hline$>2500 \mathrm{gm}$ & 119 & 78.82 \\
\hline
\end{tabular}

Of admitted 151 cases, 111 newborns (73.35\%) were of age less than 24 hours, followed by $21(13.90 \%)$ newborns with age group 1-3 days. Of total 636 neonates born, 82 neonates were of low birth weight i.e. $12.8 \%$ in total.

\begin{tabular}{|l|l|l|}
\hline \multicolumn{3}{|l|}{ Table 2. Patient Age group $(\mathrm{n}=151)$} \\
\hline Age (in Days) & Number(n=151) & Percentage \\
\hline$<1$ day & 111 & 73.35 \\
\hline $1-3$ & 21 & 13.90 \\
\hline $4-7$ & 11 & 7.28 \\
\hline $8-28$ & 8 & 5.29 \\
\hline
\end{tabular}

Regarding the length of stay, majority 55(36.42\%) of the neonates stayed for $4-7$ days followed by $39(25.82 \%), 1-3$ days \& 33(21.85\%), >7days respectively and the rest $24(15.89 \%)$ of the neonate stayed for only $<24$ hours. 
Shrestha et al. Clinical Profile and Outcome of Neonates Admitted..

\begin{tabular}{|l|l|l|}
\hline \multicolumn{3}{|l|}{ Table 3. Patient regarding length of stay } \\
\hline $\begin{array}{l}\text { Length of hospital stay } \\
\text { (in days) }\end{array}$ & Number(n=151) & Percentage \\
\hline$<1$ day & 24 & 15.89 \\
\hline $1-3$ days & 39 & 25.82 \\
\hline $4-7$ days & 55 & 36.42 \\
\hline$>7$ days & 33 & 21.85 \\
\hline
\end{tabular}

Neonatal sepsis $91(60.26 \%)$ was the most common cause of hospital admissions followed by meconium aspiration syndrome 21(13.9\%) and prematurity $10(6.62 \%)$ as shown in table 4 .

\begin{tabular}{|l|l|l|}
\hline \multicolumn{3}{|l|}{ Table 4. Spectrum of neonatal admission } \\
\hline Diagnosis & Number(n=151) & Percentage \\
\hline Sepsis & 91 & 60.26 \\
\hline $\begin{array}{l}\text { Meconium Aspiration } \\
\text { Syndrome }\end{array}$ & 21 & 13.90 \\
\hline Prematurity & 10 & 6.62 \\
\hline $\begin{array}{l}\text { Respiratory Distress } \\
\text { Syndrome }\end{array}$ & 7 & 4.63 \\
\hline Birth Asphyxia & 7 & 4.63 \\
\hline Hyperbilirubinaemia & 3 & 1.98 \\
\hline $\begin{array}{l}\text { Staphylococcal skin } \\
\text { infection }\end{array}$ & 3 & 1.98 \\
\hline Congenital Heart Disease & 2 & 1.32 \\
\hline Cellulitis & 1 & 0.66 \\
\hline Neonatal Seizure & 1 & 0.66 \\
\hline Necrotizing Enterocolitis & 1 & 0.66 \\
\hline Congenital Pneumonia & 1 & 0.66 \\
\hline Duodenal Atresia & 1 & 0.66 \\
\hline Hirschprung Disease & 1 & 0.66 \\
\hline $\begin{array}{l}\text { Syndromic Baby } \\
\text { (?Edwards Syndrome) }\end{array}$ & 1 & 0.66 \\
\hline
\end{tabular}

Maximum number of admissions was found during the month of June to August whereas minimum during the month of May and September as shown in figure 3.

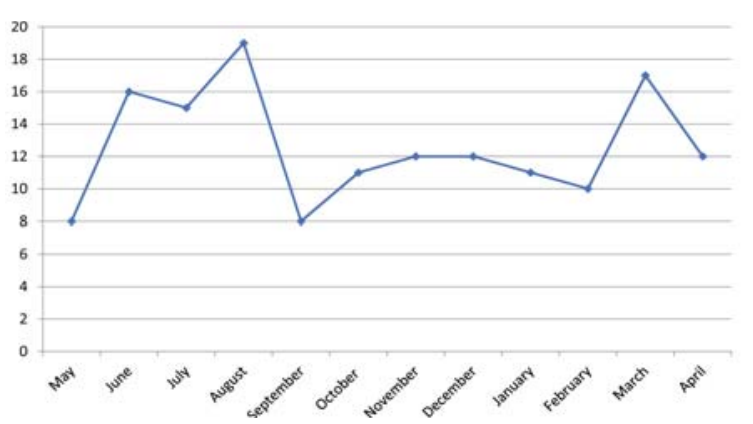

Figure 3. Monthly admission pattern of study population

112 babies (74.1\%) were discharged after improvement, 15(9.93\%) left against medical advice, $13(8.6 \%)$ babies were referred to higher centers for intensive care and there were 9 (5.9\%) mortalities and 2(1.3\%) absconded cases. 28 neonates needed resuscitation. Majority of cases were referred to higher center .

\section{Outcome of study population}

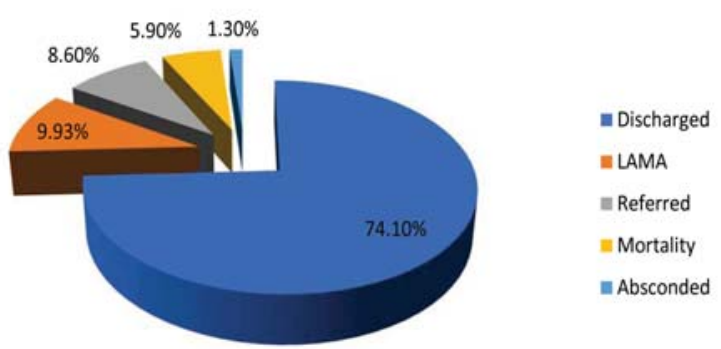

Figure 4. Outcome of study population

There was 531 (85\%) normal delivery followed by Caesarean section which was 84 i.e. $13 \%$ out of total 628 deliveries. 13 (2\%) was through Instrumental delivery.

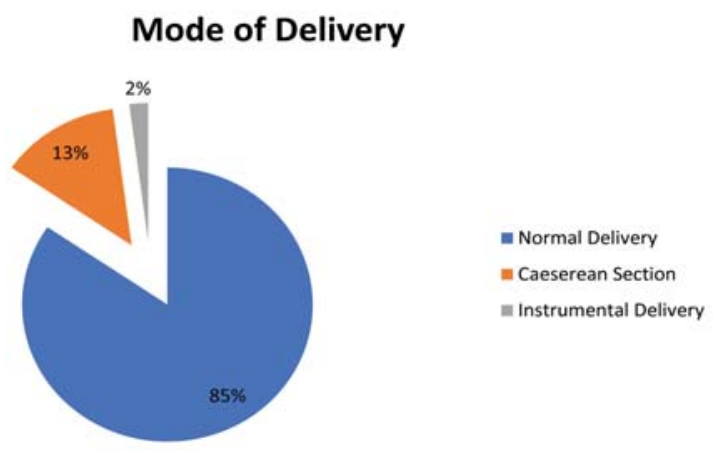

Figure 5. Mode of delivery

\section{DISCUSSION}

In our present study, total 153 newborns were admitted in neonatal unit during study period and male: female ratio was 1.6:1. In a study done by Shakya A et al in KIST Medical College, Lalitpur, there was a male predominance with a male to female ratio of $1.4: 1 .^{12}$ Similar pattern of male dominance was found in a study conducted by Shrestha SP et al in Chitwan Medical College and Teaching Hospital where they found male to female ration of $1.8: 1 .^{13}$ Kanodia $\mathrm{P}$ et al also found male predominance in a study conducted in BP Koirala Institute of Health Sciences, Dharan,

JKAHS / VOL 2 / NO.2 / ISSUE 2/ MAY-AUG, 2018 
Nepal. ${ }^{10}$ Gender bias towards male babies is a universal phenomenon and is seen in all regions and cultures. That is the reason male babies are brought in higher numbers to seek medical attention and thus have greater chance of detection of neonatal problems. ${ }^{14}$

The majorities $(80.7 \%)$ were term gestation and $19.3 \%$ were preterm in our study. Similar finding was found in a study conducted by Shakya A et al where $89.2 \%$ were term and $10.8 \%$ preterm. ${ }^{12}$ This finding was different from other centers where the percentages of premature babies were higher (23.8\% to above $50 \%) .{ }^{15-17}$ This is probably due to the fact that our hospital has only special baby care unit with no mechanical ventilators and so preterm babies are referred to higher center for further evaluation.

The number of low birth weight (LBW) babies born during study period was found to be 82 $(12.8 \%)$ i.e. 128 per 1000 live births. It is similar to a study done by Karkee $\mathrm{R}$ et $\mathrm{al}^{18}$ where the Low birth babies were $16.5 \%$. The cause of increased birth of LBW babies may be due to lack of birth preparedness, lack of information on maternal health and nutritional status and poor socioeconomic condition.

In our study, we found that most of our admissions (73.35\%) occurred during the first 24 hours of life. Kanodia $\mathrm{P}$ et al also suggested 55.5\% admissions occurred during the first 24 hour. ${ }^{10}$ Another study done by Gauchan et al found $44.5 \%$ of admissions during the same age group. ${ }^{15}$ This reemphasizes the fact that the first 24 hours of life is a period of crucial importance as neonate adapts to extrauterine environment, hence suffers from most of neonatal problems during this period. ${ }^{12}$

55(36.42\%) newborns stayed for 4-7 days in neonatal unit and least neonates (15.89\%) stayed for $<24 \mathrm{hrs}$. Similar result was found in a study done by Kanodia P et al in BPKIHS. ${ }^{10}$ This is because most of the cases were due to infection and newborns were admitted to complete the doses of antibiotics. Least patients stayed for less than 24 hrs because most of them were either referred, ex- pired or went on LAMA.

Pattern on neonatal admissions vary from place to place, however review of literature revealed that prematurity, birth asphyxia and neonatal sepsis are the common causes of newborn morbidity and mortality ${ }^{4}$. Neonatal sepsis 91 (60.26\%) was the most common cause of hospital admissions followed by meconium aspiration syndrome $21(13.9 \%)$ and prematurity $10(6.62 \%)$ in our study. Similar result was found in a study performed by Jan et al. who reported a high incidence (41.3\%) of neonatal sepsis. ${ }^{19}$ In a study conducted by Shakya A et al, the most common cause of neonatal admission was sepsis (45.9\%), followed by respiratory conditions (14.7\%), neonatal jaundice (12.5\%), perinatal asphyxia (9.3\%) and prematurity/Small for gestational age (SGA) $(6.5 \%) .{ }^{12}$ This is because neonatal sepsis may acquire during intrauterine period, during delivery time or after delivery at nursery itself. Prematurity was also an important reason for admission as suggested in our study. Similar result of $6.7 \%$ was also found in another study. ${ }^{13}$ It is because preterm neonates really require very close attention and advanced care because of their inherent problems and complications.

Similarly, in our study, $74.1 \%$ were discharged after improvement, 9.93\% left against medical advice, $8.6 \%$ babies were referred to higher centers for intensive care and there were $5.9 \%$ mortalities and $1.3 \%$ absconded cases. Most people leave against medical advice for many reasons like family, personal or financial problems, dissatisfaction with medical care given, preference for another hospital, false perception that the overlying condition was terminal as well as communication gap between health care providers and parents. ${ }^{20}$ Overall mortality observed was $4.6 \%$ in a study by Kanodia P et al which was similar as in our study. ${ }^{10}$ Actually mortality depends upon the stage of the disease and facilities available in a particular Neonatal unit. Referral was high because of lack of laboratory facilities and intensive care unit.

\section{CONCLUSIONS}

In this study, Sepsis was the leading cause of admission into the neonatal unit followed by 
meconium aspiration syndrome. Unlike other centers, perinatal asphyxia and prematurity/LBW were not as significant. Most of the morbidities and subsequently the mortalities can be minimized by improving the antenatal care of pregnant women, timely interventions and timely referral to tertiary care centers for delivery of high-risk pregnancies. We should also address the potential risks of prematurity and low-birth weight and the management of their complications. Similarly, Majority of the admissions occurred within the first 24 hours of life. So, to improve neonatal outcome, the first critical 24 hours should be addressed and intervened in time if indicated. Establishment of intensive care facility is required to lower morbidity, mortality as well as referral.

\section{Conflict of Interest: None}

\section{REFERENCE}

1. Cited from www.kahs.edu.np

2. Jehan I, Harris H, Salat S, Zeb A, Mobeen N, Pasha O. Neonatal mortality, risk factors and causes: A Prospective population- based cohort study in urban Pakistan. Bull World Health Organ 2009; 87(2): 130-8

3. Zupan J, Aahman E. Perinatal mortality for the year 2000: estimates developed by WHO. Geneva: World Health Organization; 2005

4. WHO and Maternal and Child Epidemiology Estimation Group (MCEE) provisional estimates 2015

5. UNICEF. The state of the world children 2016: A fair chance of survival for every child. 2016

6. UNICEF. Committing to child survival: A Promise Renewed-Progress Report 2015

7. Ministry of Health and Population (MOHP) [Nepal], New ERA, ICF International Inc. Nepal Demographic and Health Survey 2016. Kathmandu, Nepal: Ministry of Health and Population, New ERA, ICF International; Nov 2017

8. Aurangzeb B, Hameed A. Neonatal sepsis in hospital born babies: bacterial isolates and antibiotic susceptibility patterns. J Coll Physicians Surg 2003; 13:629-32

9. Lawn JE, Wilczynska-ktende K, Cousens SN. Estimating the causes of four million deaths in the year
2000. Int J Epidemiol. 2006 Jun: 35 (3); 718-9

10. Yasmeen S, Waheed KA, Gul R.Spectrum of neonatal admissions and their outcome in a tertiary care hospital.Pak Armed Forces Med J 2017; 67 (6): 1044-49

11. Shakya A, Shrestha D, Shakya H, Shah SC, Dhakal AK. Clinical profile and outcome of neonates admitted to the Neonatal Care Unit at a teaching hospital in Lalitpur, Nepal. Journal of Kathmandu Medical College :2014 Oct-Dec; 3(4) :144-48

12. Shrestha SP,Shah AK,Prajapati R,Sharma YR. Profile of neonatal admission at Chitwan Medical College. Journal of Chiwan Medical College 2013;3(6):13-16

13. Bucens IK, Reid A, Barrreto AC, Dwivedi V, Counahan M. Three years of neonatal morbidity and mortality at national hospital in Dili, East Timor. J Paediatr Child Health 2013; 49(12): 1004-9

14. Gauchan E, Basnet S, Koirala DP, Rao KS. Clinical profile and outcome of babies admitted to neonatal intensive care unit (NICU). J Inst Med. 2011;33(2):1-8

15. Shah GS, Yadav S, Thapa A, Shah L. Clinical Profile and Outcome of Neonates Admitted to Neonatal Intensive Care Unit (NICU) at a Tertiary Care Centre in Eastern Nepal. J Nep Paediatr Soc. 2013;33(3):17781

16. Shrestha S, Karki U. Indications of admission and outcome in a newly established neonatal intensive care unit in a developing country (Nepal). Nepal Med Coll J. 2012;14(1):64-7

17. Karkee R, Lee AH, Binns CW. Incidence of Low Birth Weight in Central Nepal: A Community-Based Prospective Cohort Study. Matern Child Health J.2015; 19:1-5

18. Jan AZ, Ahmad S, Zahid SB. Clinical audit of admission pattern and its outcome in a Neonatal ICU. Gomal J Med Sci 2013; 11: 31-6

19. Al-Turkistani HK. Discharge against medical advice from Neonatal Intensive Care Unit: 10 years' experience at a University Hospital. J Fam Comm Med 2013; 20(2): 113-15 